\title{
Total kalça artroplastisinde aşınma ve osteoliz
}

\author{
Wear and osteolysis in total hip arthroplasty
}

\author{
Murat Köken ${ }^{1,2}$, Ahmet Hakan Kara ${ }^{3}$ \\ ${ }^{1}$ Antalya Bilim Üniversitesi, Sağlık Hizmetleri Meslek Yüksekokulu, Antalya, Türkiye \\ ${ }^{2}$ Medicalpark Antalya Hastanesi, Antalya, Türkiye \\ ${ }^{3}$ Özel Akdamar Hastanesi, Van, Türkiye
}

Total kalça artroplastinin orta ve uzun dönem sonuçlarında implant yetmezliğine yol açan aşınma ve osteoliz uzun zamandır üzerinde tartışılan bir konudur. Teknolojinin ve cerrahi tekniklerin gelişmesine rağmen revizyon cerrahilerinin en büyük sebeplerinden biri olmaya devam etmektedir. Aşınma ve osteoliz mekanizmaları ile tedavi seçeneklerinde henüz altın standart bulunmamaktadır. Ortopedi ve travmatoloji uzmanının, kullanacağı cerrahi tekniği bilmesi ve malzemelere hâkim olması, planlamasını ona göre yapması çok önemlidir.

Anahtar sözcükler: total kalça artroplastisi; osteoliz; aşınma
Wear and osteolysis leading to implant failure in medium and long-term results in total hip arthroplasty has been a controversial topic for a long time. Despite the development of technology and surgical techniques, it continues to be one of the biggest reasons for revision surgeries. There is no gold standard yet for treatment options with wear and osteolysis mechanisms. It is very important for the orthopaedics surgeon to master the surgical technique and materials to be used, and to plan accordingly.

Key words: total hip arthroplasty; osteolysis; wear

tespitinin kaybı olarak tanımlanır. Genellikle aseptik gevşeme, osteoliz ve kemik yeniden şekillenmesinin bir sonucu olarak önemli oranda periprostetik kemik kaybı ile ilişkilidir. Klinik semptomlar sıktır ve bir revizyon ihtiyacını doğurur. ${ }^{[5]}$

\section{OSTEOLIZLE ÍLGILi AŞINMA DEBRISi}

Aşınma debrisi, osteolizin en önemli sebeplerinden biri olup biyolojik cevapları anlayabilmek için sık görülen tiplerini inceleyeceğiz. Total kalça artroplastisi uygulanmış hastalarda aşınma debrisi çeşitli sebeplerden ötürü ortaya çıkabilmektedir. Debris yükünün \%75-\%95'lik kısmını UHMWPE partikülleri oluşturmaktadır. ${ }^{[9,10]}$ Osteolitik dokularda baskın debris tipini bu partiküller oluşturur. UHMWPE debrisi, gevşemiş kalça artroplastilerinde geri kazanılan ve analiz edilen dokularda bulunur. Buna rağmen son dönemlerde çıkan çapraz bağlı UHMWPE, kalça simülasyonlarında aşınmada önemli derecede azalma sergilemektedir. ${ }^{[11,12]}$ Yapılan analizlerde, eski nesil UHMWPE'lerin aksine, çapraz bağlı yeni nesil UHMWPE'lerde fibril yapıları görülmemiştir. ${ }^{[13,14]}$ Ancak çapraz bağlı UHMWPE'lerin de yaklaşık 2-4

iletişim / Contact: Doç. Dr. Murat Köken • E-posta / E-mail: drmuratkoken@gmail.com

ORCID iD: Murat Köken, 0000-0001-9180-0625 • Ahmet Hakan Kara, 0000-0001-7501-2135

Geliş / Received: 9 Eylül 2021 • Kabul / Accepted: 20 Eylül 2021 
kat daha fazla enflamatuvar mediyatör oluşturduğu tespit edilmiştir. ${ }^{[15]} \mathrm{Bu}$ durum yeni bir endişe konusunun ortaya çıkmasına sebebiyet vermiştir.

Metalik debris bir başka önemli debris tipi olup en önemli kaynağının modüler femur başı ve boyun bileşkesi olduğu tespit edilmiştir. Sürtünme, özellikle çok modüllü komponentlerde, metal debrisinin önemli bir kaynağı olarak görülmektedir. Ayrıca silikatlar ve paslanmaz çelikte az miktarda görünmekte olup, buna cerrahi aletlerin kontaminasyonunun sebep olduğu düşünülmektedir. ${ }^{[16]}$ Bunlar küçük miktarlarda partiküller olmasına karşın agresif hücresel cevaba sebep olarak enflamatuvar cevabı başlatabilmektedir. Ayrıca yapı olarak sert olan bu debrislerin, baş ile UHMWPE yüzeyleri arasına girerek üçüncü cisim aşınmasında (third body wear) ve UHMWPE aşınma debrisi oluşumunda artışa sebep olduğu düşünülmektedir.

Yapılan analizlerde tespit edilen birçok partikül debrisi saptanmasına rağmen granülamatöz reaksiyonu hangisinin veya hangilerinin başlattığı tespit edilememiştir. ${ }^{[16]}$ Granülamatöz reaksiyona neden olan debris tipinin tespiti için daha çok çalışmaya ihtiyaç vardır.

\section{Makrofaj Partikül Etkileşimi}

Makrofajların ve yabancı cisim dev hücrelerinin, periprostetik granüloma ve kemik erezyonunda mevcudiyeti saptanmış bir gerçektir. ${ }^{[17-19]}$ Makrofajlar her türlü enflamasyonun ve immun cevabın birincil hücreleri olma görevindedir. Makrofajlar, debrise karşı yanıt vererek osteoklastların çağrılması, proliferasyonu, diferansiyasyonu ve olgunlaşması için gerekli mediyatörlerin salgılanmasını gerçekleştirir. ${ }^{[20-22]} \mathrm{Bu}$ olaylar zinciri kemik ile implant arasındaki oluşan bağlantıları parçalayarak implantın gevşemesine neden olmaktadır. Klinik çalışmalarda fagosite edilebilen büyüklükte kobalt, nikel ve kobalt-krom alaşım partikülleri fagositöz yeteneklerini azaltmaktadır ve hücrenin ölümüne yol açabilecek şekilde hücre zarında hasar oluşturduğu görülmektedir. Titanyum partiküllerinin daha az miktarda zarar verdiği de saptanmıştır. ${ }^{[23-25]}$ UHMWPE ve polimetilmetakrilatın ise çok daha az miktarda zarar verdiği ortaya konulmuştur. ${ }^{[26,27]}$ Partikül toksisitesi, hücrelerin mediyatör salınım yeteneğini de olumsuz etkilemektedir. Örneğin, kobalt-krom alaşım partiküllerinin çok kısa sürede önemli miktarda makrofaj ölümüne ve düşük miktarda enflamatuvar mediyatör salınımına sebep olduğu gösterilmiştir. ${ }^{[28]}$ Titanyum alaşım partiküllerinin ise diğer alaşımlara göre çok daha az toksik olduğu saptanmış ve 24 saatten uzun sürede hücre ölümüne sebep olduğu gösterilmiştir. Ayrıca makrofajlarda daha yüksek miktarda mediyatör salınımı gerçekleşmiştir. UHMWPE aşınma debrisinin metal partiküllere oranla çok daha az uyarıcı olduğu ancak stimüle edilmemiş hücrelere oranla anlamlı derecede daha fazla stimüle edici olduğu tespit edilmiştir. ${ }^{[29,30]}$ Enzimler, mediyatörler ve enflamatuvar sitokinler kemik rezorpsiyonunda önemli derecede stimüle edici bir role sahiptir. Prostoglandin E2 (PG E2), interlökin 1 (IL-1) ve tümör nekroz faktör- $\alpha$ (TNF- $\alpha$ ) osteoklastlar üzerinden güçlü stimülatörlerdir. Aşınma debrisi, cerrahi olarak kalvaryuma yerleştirilse bile makrofaj cevabı kemik rezorpsiyonunun enflamatuvar cevabını başlatabilir (Şekil 1). ${ }^{[27,30]}$

\section{Makrofaj Etkisinin Anti-inflamatuvar Komponenti}

İn vitro olarak partiküllerle stimüle edilen makrofajlarda bol miktarlarda vasküler endotelyal büyüme faktörü (VEGF) bulunmaktadır. ${ }^{[31]}$ Ayrıca makrofajların büyüme faktörleri salarak fibroblast proliferasyonunu da stimüle ettikleri gösterilmiştir. ${ }^{[29]}$ Makrofajların partikül yönetimli enflamasyonda birleştirici bir cevap oluşturduğu düşünülmektedir. Bu iyileştirici durum, implant çevresinde bulunan dokularda devam etmektedir. Kemik rezorbe oldukça oluşan boşluklar vaskülarize interfasiyel dokularla doldurulmaktadır. ${ }^{[32,33]}$

\section{Aşınma Debrisinin Osteoblastlar Üzerindeki Etkileri}

Normal fizyolojik şartlar altında osteoklastik kemik rezorpsiyonu osteoblastik aktivite ile dengelenmektedir. ${ }^{[34]}$ Osteoblastik aktivite, kemik ve implant arasında hayati önem taşımaktadır. Bu denge bozulur ise debrisin oluşturduğu enflamasyona bağlı kemik kaybı yerine konulamaz. Partiküller osteoblastik aktiviteyi baskılayarak bu dengeyi bozar. Debris osteoklastik proliferasyonu stimüle eder iken aynı zamanda PGE2 üretimini de stimüle ederek hücresel diferansiyasyonu ve hücre dışı matriks sentezini de inhibe etmektedir. ${ }^{[35]}$

Aşınma debrisi IL-1, IL-6, TNF- $\alpha$ gibi enflamatuvar mediyatörler ile osteoklast diferansiyasyonunu ve aktivasyonunu stimüle etmektedir. Aynı mediyatörler osteoblastik aktiviteyi ve matriks sentezini baskılamaktadır. Aşınma debrisi, aynı zamanda fibroblast aktivitesini de stimüle etmektedir. ${ }^{[32,34,36]}$

Bunların sonucu olarak, osteoklastik aktivite sonucu rezorbe olan kemiğin yerini fibröz doku doldurur ve implant tespitinde kayıp gerçekleşir (Şekil 2).

\section{OSTEOLIZIN TEDAVI YÖNETIMi}

Kemik rezorpsiyonundan birincil olarak sorumlu mediyatör araştırılmaktadır. Burada asıl amaç kilit 


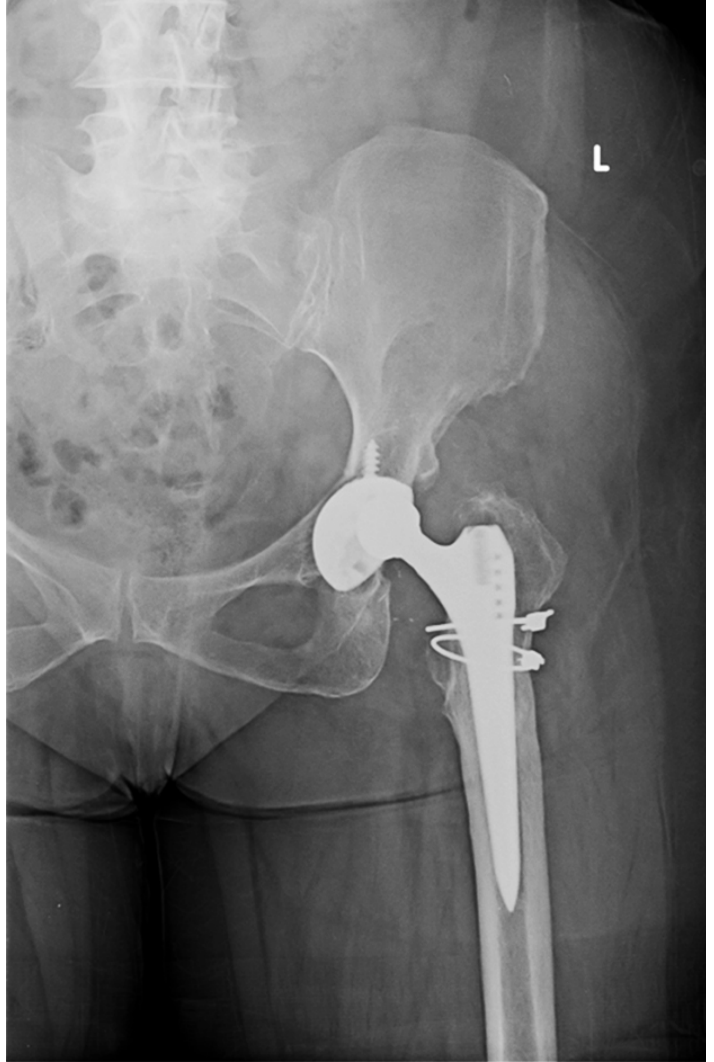

Şekil 1. Sol tip 3 kalça çıkığı koksartroz nedeniyle total kalça protezi uygulanmış, subtrokanterik transverse osteotomi yapılan hastanın ameliyat sonrası 14 . yılda polietilen insert aşınması, asetabular komponentte osteoliz ve asetabular gevşeme görülmekte (femoral stemde tutunma ve stabilite tatminkar görülmektedir). (Prof. Dr. Berk Güçlü'nün arşivinden)

mediyatörü bloke ederek enflamatuvar kaskadı önlemektir. ilk olarak non-steroid anti-enflamatuvar ilaçlar kullanılmış ve iyi sonuçlara ulaşılamamıştır.

\section{Anti-Tümör Nekroz Faktör (TNF) Tedaviler}

Bu tedaviler, araştırmaları osteolizi en fazla stimüle eden osteoklast diferansiyasyonu ve stimülasyonuna yol açan TNF- $\alpha$ üzerine yoğunlaştırdı. ${ }^{[36]}$ Deneysel çalışmalar bu hipotezi destekledi. Bu deney sonuçları, belirgin osteolizin görüldüğü hastalarda Etanercept' in kullanıldığı klinik deneyler için yolu açtı. ${ }^{[36,37]}$ Etanercept ve plasebo şeklinde iki gruba ayrılan hastalarda, bir yıllık klinik deney sonunda, Etanercept lezyonun büyüklüğünü etkilemedi. Her iki grup hastada osteolitik lezyon büyüklüklerinin arttığı görüldü. Bu çalışmanın sonucuna göre, tek bir enflamatuvar mediyatör yerine enflamatuvar mediyatörler panelinin enflamasyonu birlikte yönettiği ve osteoklast stimülasyonuna giden başka yollar olduğu düşünülebilir. ${ }^{[38]}$

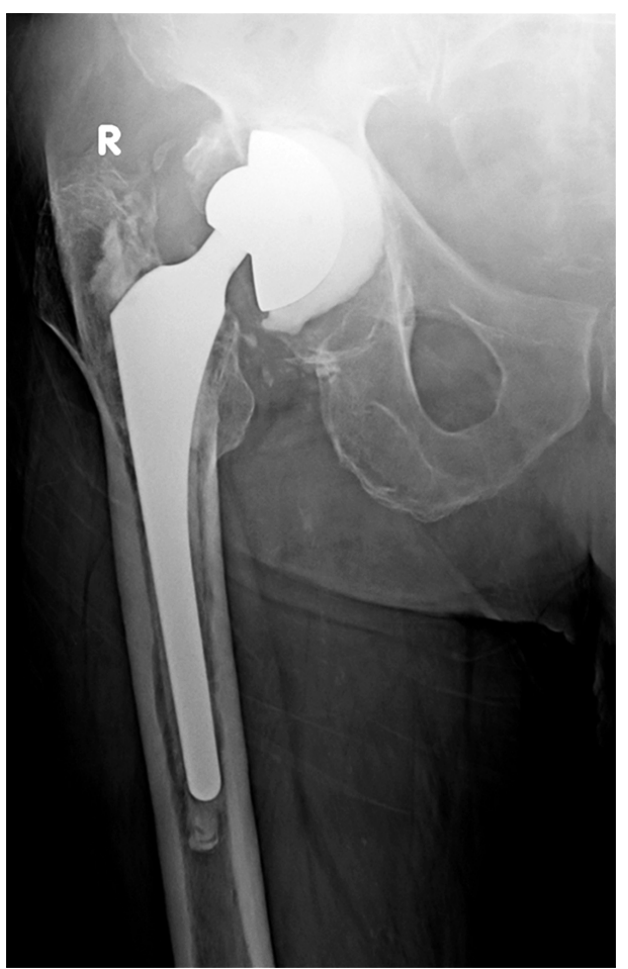

Şekil 2. Çimentolu total kalça protezi yapılmış hastanın osteoliz sonrası implant gevşemesi; hem asetabular hem de femoral komponentlerde stabilite kaybı. (Prof. Dr. Berk Güçlü'nün arşivinden)

\section{Bisfosfonat Tedavileri}

Sementsiz TKA köpek modelinde UHMWPE partiküllerinin stimüle ettiği osteoliz önlenmesinde oral bisfosfonat etkisi değerlendirildi. Bu çalışmada, cerrahiden 24 hafta sonra tedavi edilmeyen köpeklerde implantların çevresinde radyolusent görünüm ve aseptik gevşemeyle uyumlu endosteal çatlaklar ortaya çıkmıştı. Oral alendronat ile tedavi edilen modellerde osteklastlar ile stimüle olan kemik rezorpsiyonu tamamen inhibeydi. Aşınma debrisine karşı altta yatan enflamasyon az da olsa devam ediyordu. Makrofajlar aşınma debrisi ile stimüle olsalar bile bisfosfonat tedavisi osteoklastları çevre kemiği aşındırmaktan engelleyebiliyordu. ${ }^{[39]} \mathrm{Bu}$ bulgu bisfosfonatları bilinen hiçbir anti-enflamatuvar etki yapmadan spesifik olarak inhibe ettikleri şeklinde gösterilmiştir.

Klinik ortamlarda sonuçlar bu kadar iyimser değildir. Lyons ve ark., aseptik gevşeme belirtileri gösteren ve revizyon cerrahisi için bekleyen hastalarda alendronat tedavisini incelediler. Bu hasta grubunda altı aylık oral alendronat tedavisi revizyon cerrahisi ihtiyacını ortadan kaldırmamış ve herhangi bir avantaj ortaya koymamıştır. ${ }^{[40]}$ 


\section{Stres Kalkanının Önlenmesi}

Bisfosfonatların stres kalkanı nedeniyle diffüz kemik kaybını önleyebildiği klinik kanıtlarla desteklenmiştir. ${ }^{[1]}$ Kalça replasmanında metalik implantların çevredeki kemik üzerinde yüklenme örtüsünü değiştirdiği bilinmektedir. Kalça replasmanı sonrası ilk üç aylık sürede kemik mineral dansitesi implant çevresindeki tüm kemik dokuda \%3-\%14 azalmaktadır. ${ }^{[42]}$ Bu azalmanın büyük bir kısmı ilk bir yıl içerisinde olmaktadır. Daha sonraki yıllarda azalma miktarı azalır, hatta hafif bir restorasyon görülür. Bir hayvan modelinde, ameliyattan bir ay önce başlanmak üzere aylık uygulanan zoledronat infüzyonunun kemik rezorpsiyonunu azalttığı ve implantasyon sonrası dört aydan uzun bir süre stres kalkanının yıkıcı etkisini önlediği gösterilmiştir. ${ }^{[41]}$ Bisfosfonat tedavisinin, kalça replasmanı yapılmış hastalarda kemik kalitesinin korunmasında ve bu durumun uzun süre muhafaza edilmesinde yararlı olduğu gösterilmiştir. ${ }^{[41]}$

\section{İmplant Stabilitesinde İyileştirme}

Çimentosuz kalça replasmanının uzun vadeli başarısında ilk biyolojik tespitin stabil olması ciddi derecede önemlidir. İmplant migrasyonu özellikle cerrahiden ilk altı ay sonraki dönemde olmaktadır. Bu migrasyon bir yıldan fazla sürer ise gevşeme meydana gelmektedir. ${ }^{[43]}$ Bisfosfonat tedavisi implantları stabilize etmekle beraber komponentleri migrasyondan bir yıl süresince korumaktadır. ${ }^{[41]}$

Son zamanlarda bazı genleri hedef alan terapötik ajanlarla ilgili de çalışmalar yapılmaktadır. Goater ve ark., partiküllerle indüklenen fare kalvaryumunda Osteoprotegerin (OPG) ko-ekspresyonu yapan adenoviral vektörün intramusküler enjeksiyonu ile osteolizin tamamen inhibe olduğunu gösterdiler. ${ }^{[4]}$ IL reseptör antagonist protein kullanılarak IL-1 etkisi bloke edilerek, UHMWPE ile indüklenen enflamatuvar sitokinlerin bloke edildiği gösterilmiştir. ${ }^{[45,46]}$

\section{GELECEKTE IZLENECEK YOL}

Aşınma debrisini azaltacak her yol, eklem replasmanlarının ömrünü uzatacaktır. Çapraz bağIı UHMWPE'nin eklem replasmanlarının ömrünü uzatma ümidi vardır. XPLE (Cross-Linked Polyethylene - çapraz bağ|ı polietilen) ara parçalar (liner) debris oluşumunu \%90 azaltabilmekte, ancak bu ara parçalardan gelen debris makrofajlar için geleneksel UHMWPE'den daha fazla enflamatuvar etki oluşturmaktadır. ${ }^{[15,47]}$ Sonuç olarak, agresif bir yaklaşımla, ilk osteoliz veya ilk aşınma belirtisinde ara parçaların değiştirilmesi gerekmektedir. XPLE debrisinin araştırılması ve daha çok veri gerekmektedir.
Terapötik ajanlarla enflamatuvar etkileri bloke etme yöntemi şimdiye kadar başarısız olmuştur. Hayvan modellerinde iyi sonuçlara rağmen, insan modelinde alınan cevaplar olumsuzdur. Bunun sebeplerinden biri, hastalarda güvenli bir terapötik pencere elde edilememiş olması olabilir. ${ }^{[45,46]}$ Bu çalışmalarda, tek bir mediyatörden ziyade aralarında daha karmaşık ilişki bulunan bir mediyatörler panelinin, aşınma debrisi ile artan osteoliz yükü arasındaki bağlantısından da kaynaklanabilir. ${ }^{[47]}$

Gen tedavisi gelecek için umut olabilir. Viral vektörler kullanılarak gen aktarımı, tartışmalı bir konudur. Küçük hayvanlarda dramatik sonuçlar ortaya çıksa da klinik gerçekler bu durumu bozabilir. ${ }^{[48]}$

Bisfosfonatlar, özellikle yaşı eklem replasmanı hastalarında umut vermeye devam etmektedir. Osteolizin tedavisinde bisfosfonatların işe yaraması için, osteoliz klinik başlangıcında kullanılmaya başlanmalıdır. Lezyon hâlâ küçük, asemptomatik ve implant stabil ise bisfosfonatlar denenebilir. Litik lezyon hızla genişliyorsa, implant zaten gevşemiş veya gevşeme kaçınılmaz ise bisfosfonatlar çok işlevsel değildir. Klinik deneysel hastalar için uygun bisfosfonat dozlarının belirlenmesi gerektiğini göstermektedir. ${ }^{[41]}$

Mevcut tedavi yöntemlerinin karmaşıklığına uygun olarak, tedavi etkinliğinin de hassas yöntemlerle izlenmesi gerekmektedir. Röntgen ve bilgisayarlı tomografi taramaları, klinik çalışmalarda sınırlamaları ortaya çıkartmıştır. Önemli olan, kemik rezorpsiyonunun erken döneminde, implant stabilitesi bozulmadan ve revizyon cerrahisini gerektirmeden önce teşhis koyabilmektir.

Tedavi için geliştirilen en önemli konulardan birisi maliyettir. Etanercept'in bir yıllık maliyeti yaklaşık 10.000 dolar, revizyon cerrahisinin maliyeti yaklaşık 31.000 dolardır. ${ }^{[48]}$ Gen tedavisinin maliyeti henüz belirlenememiştir.

\section{KAYNAKLAR}

1. Charnley J. The long-term results of low-friction arthroplasty of the hip performed as a primary intervention. J Bone Joint Surg Br 1972;54(1):61-76. https://pubmed.ncbi.nlm.nih. gov/5011747/

2. Schulte KR, Callaghan JJ, Kelley SS, Johnston RC. The outcome of Charnley total hip arthroplasty with cement after a minimum twenty-year follow-up. The results of one surgeon. J Bone Joint Surg Am 1993;75(7):961-75. Crossref

3. Wroblewski BM. 15-21-year results of the Charnley lowfriction arthroplasty. Clin Orthop Relat Res 1986;(211):305. Crossref

4. Barrack RL, Mulroy RD Jr, Harris WH. Improved cementing techniques and femoral component loosening in young patients with hip arthroplasty. A 12-year radiographic review. J Bone Joint Surg Br 1992;74-B(3):385-9. Crossref 
5. Espehaug B, Havelin LI, Engesaeter LB, Langeland N, Vollset SE. Patient-related risk factors for early revision of total hip replacements. A population register-based case-control study of 674 revised hips. Acta Orthop Scand 1997;68(3):207-15. Crossref

6. Hozack WJ, Rothman RH, Booth RE Jr, Balderston RA, Cohn JC, Pickens GT. Survivorship analysis of 1,041 Charnley total hip arthroplasties. J Arthroplasty 1990;5(1):41-7. Crossref

7. Schmalzried TP, Shepherd EF, Dorey FJ, Jackson WO, dela Rosa M, Fa'vae F, McKellop HA, McClung CD, Martell J, Moreland JR, Amstutz HC. The John Charnley Award. Wear is a function of use, not time. Clin Orthop Relat Res 2000;381:36-46. Crossref

8. Harris WH. The problem is osteolysis. Clin Orthop Relat Res 1995;(311):46-53. https://pubmed.ncbi.nlm.nih.gov/7634590/

9. Abb J, Zander H, Abb H, Albert E, Deinhardt F. Association of human leucyte low reponsiveness to inducers of interferon alpha with HLA-DR2. Immunology 1983;49(2):239-44. https://www.ncbi.nlm.nih.gov/pmc/articles/PMC1454175/

10. Friedman RJ, Black J, Galante JO, Jacobs JJ, Skinner HB. Current concepts in orthopaedic biomaterials and implant fixation. Instr Course Lect 1994;43:233-55. https://pubmed. ncbi.nlm.nih.gov/9097153/

11. McKellop H, Shen FW, Lu B, Campbell P, Salovey R. Devalopment of an extremely wear-resistant ultra high molecular weight polyethylene for total hip replacements. J Orthop Res 1999;17:157-67. Crossref

12. Muratoglu OK, Bragdon CR, O'Connor DO, Jasty M, Harris $\mathrm{WH}$. A novel method of cross-linking ultra-high-molecularweight polyethylene to improve wear, reduce axidation, and retain mechanical properties. Recipient of the 1999 HAP Paul Award. J Artroplasty 2001;16(2):149-60. Crossref

13. Ries MD, Scott ML, Jani S. Relationship between gravimetric wear and particle generation in hip simulators: coventional compared with cross-linked polyethylene. J Bone Joint Surg Am 2001;83-A (Suppl 2, Pt 2):116-22. Crossref

14. Shanbhag AS, Vai CW, QureshiSA, Rubash HE. Characteristics of cross-linked UHMWPE wear debris. Trans Orthop Res Soc 2001;26:2. https://www.ors.org/Transactions/47/0002.pdf

15. Huddleston JI, Hayata K, Kawashima M, Rubash HE, Shanbhag A. Human macrophage response to highly crosslinked UHMWPE debris. Trans Orthop Res Soc 2006;31:700. http://www.ors.org/Transactions/52/0700.pdf

16. Shanbhag AS, Jacobs JJ, Glant TT, Gilbert JL, Black J, Galante JO. Composition and morphology of wear debris in failed uncemented total hip replacement. J Bone Joint Surg $\mathrm{Br}$ 1994;76(1):60-7. https://pubmed.ncbi.nlm.nih.gov/8300684/

17. Coleman DL, King RN, Andrade JD. The foreign body reaction: a chronic inflammatory response. J Biomed Mater Res 1974;8(5):199-211. Crossref

18. Nakashima $Y$, Sun DH, Trindade MC, Chun LE, Song Y, Goodman SB, Schurman DJ, Maloney WJ, Smith RL. Induction of macrophage $\mathrm{C}-\mathrm{C}$ chemokine expression by titanium alloy and bone cement particles. J Bone Joint Surg $\mathrm{Br}$ 1999;81(1):155-62. Crossref

19. Lee SE, Chung WJ, Kwak HB, Chung CH, Kwack KB, Lee ZH, Kim $\mathrm{HH}$. Tumor necrosis factor- alpha supports the survival of osteoclasts through the activation of Akt and ERK. J Biol Chem 2001;276(52):49343-9. Crossref

20. Kobayashi K, Takahashi N, Jimi E, Udagawa N, Takami M, Kotake S, Nakagawa N, Kinosaki M, Yamaguchi K, Shima N, Yasuda H, Morinaga T, Higashio K, Martin TJ, Suda T. Tumor necrosis factor alpha stimulators osteoclast differantiation mechanism independent of the ODF/RANKL-RANK interaction. J Exp Med 2000;191(2):275-86. Crossref
21. Lacey DL, Timms E, Tan HL, Kelley MJ, Dunstan CR, Burgess T, Elliott R, Colombero A, Elliott G, Scully S, Hsu H, Sullivan J, Hawkins N, Davy E, Capparelli C, Eli A, Qian YX, Kaufman S, Sarosi I, Shalhoub V, Senaldi G, Guo J, Delaney J, Boyle WJ. Osteoprotegerin ligand is a cytokine that regulates osteoclast differantiation and activation. Cell 1998;93(2):165-76. Crossref

22. Lum I, Wong BR, Josien R, et al. Evidance for a role of a tumor necrosis factor-alpha (TNF-alpha) converting enzymelike protease in shedding of TRANCE, a TNF family member involved in osteoclastogenesis and dendritic cell survival. J Biol Chem 1999;274(19):13613-8. Crossref

23. Garrett R, Wilksch J, Vernon-Roberts B. Effects of cobaltchrome alloy wear particles on the morpholgy, viability and phagocytic activity of murine macrophages in vitro. Aust J Exp Biol Med Sci 1983;61 (Pt 3):355-69. Crossref

24. Rae T. The biological response to titanium and titianiumaluminum-vanadium alloy particles. 1: Tissue culture studies. Biomaterials 1986;7(1):30-6. Crossref

25. Rae T. A study on the effects of particulate metals of orthopaedic interest on murine macrophages in vitro. J Bone Joint Surg Br 1975;57-B(4):444-50. Crossref

26. Horowitz SM, Doty SB, Lane JM, Burstein AH. Studies of the mechanism by which the mechanical failure of polymethylmethacrylate leads to bone resorption. J Bone Joint Surg Am 1993;75(6):802-13. Crossref

27. Horowitz SM, Gautsch TL, Frondoza CG, Riley Jr L. Macrophage exposure to polymethyl methacrylate least to mediator release and injury. J Orthop Res 1991;9(3):406-13. Crossref

28. Haynes DR, Rogers SD, Hay S, Pearcy MJ, Howie DW. The differences in toxicity and release of bone-resorbing mediators induced by titanium and cobalt-chromium-alloy wear particles. J Bone Joint Surg Am 1993;75(6):825-34. Crossref

29. Shanbhag AS, Jacobs JJ, Black J, Galante JO, Glant TT. Effect of particles on fibroblast proliferation and bone resorption in vitro. Clin Orthop Relat Res 1997;(342):205-17. https:// pubmed.ncbi.nlm.nih.gov/9308543/

30. Shanbhag AS, Jacobs JJ, Black J, Galante JO, Glant TT. Human monocyte response to particulate biomaterials generated in vivo and in vitro. J Orthop Res 1995;13(5):792801. Crossref

31. Miyanishi K, Trindade MC, Ma T, Goodman SB, Schurman DJ, Smith RL. Periprosthetic osteolysis induction of vascular endothelial growth factor from human monocyte/ macrophages by orthopaedic biomaterial particles. J Bone Miner Res 2003;18(9):1573-83. Crossref

32. Diegelmann RF, Coben IK, Kaplan AM. Effect of macrophages on fibroblast DNA synthesis and proliferation. Proc Soc Exp Biol Med 1982;169(4):445-51. Crossref

33. Diegelmann RF, Coben IK, Kaplan AM. The role of macrophages in wound repair: a review. Plast Reconstr Surg 1981;68(1):107-13. Crossref

34. Vaes G. Cellular biology and biomechemical mechanism of bone resorption: a rewiev of a recent developments on the formation, activation, and mode of action of osteoclasts. Clin Orthop Relat Res 1988;(231):239-71. https://pubmed. ncbi.nlm.nih.gov/3286076/

35. Dean DD, Shwartz Z, Liu Y, Blanchard CR, Agrawal CM, Mabrey JD, Sylvia VL, Lohmann CH, Boyan BD. The effect of ultra-high molecular weight polyethylene wear debris on MG63 osteosarcoma cells in vitro. J Bone Joint Surg Am 1999;81(4):452-61. Crossref 
36. Ingham E, Fisher J. Thre role of macrophages in osteolysis of total joint replacement. Biomaterials 2005;26(11):1271-86. Crossref

37. Smith SE, Harris WH. Total hip arthroplasy performed with insertion of the femoral component with cement and the acetabular component without cement: ten- to thirteen-year results. J Bone Joint Surg Am 1997;79(12):1827-33. Crossref

38. Childs LM, Goater JJ, O'Keefe RJ, Schwarz EM. Efficacy of etanercept for wear debris-induced osteolysis. J Bone Miner Res 2001;16(2):338-47. Crossref

39. Shanbhag AS, Hasselman CT, Rubash HE. The John Charnley Award Inhibition of wear debris osteolysis in a canine total hip arthroplasty model. Clin Orthop Relat Res 1997;(344):3343. https://pubmed.ncbi.nlm.nih.gov/9372756/

40. Lyons AR, Owen JE, Freedholm DA, et al. Effect of alendronate on periprosthetic bone mass. Transactions of the 10th Combined Meeting of the Orthopaedic Associations of the English Speaking World; Auckland, New Zealand; February 1-6, 1998. p.209.

41. Goodship AE, Lawers TJ, Green J, et al. The use of bisphosphonates to inhibit mechanically related bone loss in aspetic loosening of hip protheses. Trans Orthop Res Soc 1998;23:2.

42. Venesmaa PK, Kröger HP, Miettinen HJ, Jurvelin JS, Suomalainen OT, Alhava EM. Monitoring of periprosthetic BMD after uncemented total hip arthroplasty with dualenergy x-ray absorptiometry: a 3-year follow-up study. J Bone Miner Res 2001;16(6):1056-61. Crossref
43. Ryd I, Albrektsson BE, Carlsson I, Dansgård F, Herberts $P$, Lindstrand A, Regnér L, Toksvig-Larsen S. Roentgen stemophotogrammetric analysis as a predictor of mechanical loosening of knee protheses. J Bone Joint Surg Br 1995;77$B(3): 377-83$. Crossref

44. Goater JJ, O'Keefe RJ, Rosier RN, Puzas JE, Schwarz EM. Efficacy of ex vivo OPG gene terapy in preventing wear debris induced osteolysis. J Orthop Res 2002;20:169-73. Crossref

45. Yang SY, Wu B, Mayton L, Evans CH, Robbins PD, Wooley $\mathrm{PH}$. IL-1 Ra and Vil-10 gene transfer using retroviral vectors ameliorates particle-associated inflammation in the murine air pouch model. Inflamm Res 2002;51(7):342-50. Crossref

46. Yang SY, Wu B, Mayton I, Mukherjee P, Robbins PD, Evans $\mathrm{CH}$, Wooley $\mathrm{PH}$. Protective effects of IL-1Ra vILI-10 gene transfer on a murine model of wear debris-induced osteolysis. Gene Ther 2004;11(5):483-91. Crossref

47. Fisher J, McEwen HMJ, Tipper JI, Galvin AL, Ingram J, Kamali A, Stone $\mathrm{MH}$, Ingham E. Wear, debris, and biologic activity of cross-linked polyethylene in the knee: benefits and potential concerns. Clin Orthop Relat Res 2004;(428):114-9. Crossref

48. Frankowski JJ, Watkins-Castillo S. Primary Total Knee and Hip Arthroplasty Projections for the US Population to the Year 2030. Rosemont, IL: American Academy of Orthopaedic Surgeons; 2002. 